\title{
DESENVOLVIMENTO EM CAMPO DE FEIJÃO-CAUPI (BRS GUARIBA), EM DUAS DIFERENTES SITUAÇÕES: COM CONTROLE E SEM CONTROLE DE PLANTAS DANINHAS
}

\section{DEVELOPMENT IN BEAN COUNTRY-CAUPI (BRS GUARIBA), IN TWO DIFFERENT SITUATIONS: WITH CONTROL AND WITHOUT CONTROL OF DANINAS}

Antonia Santos Rodrigues ${ }^{1}$; Sebastião Conceição de Jesus ${ }^{2}$; Loirilene Rodrigues Carria ${ }^{3}$; Eulane Rys Rufino Abreu ${ }^{4}$; Maiany Gonçalves de Carvalho ${ }^{5}$

DOI: https://doi.org/10.31692/978-65-991061-7-0.493-495

\section{INTRODUÇÃO}

O feijão-caupi (feijão-macaça, feijão-macáçar ou feijão-de-corda), Vigna unguculata (L.) Walp., é uma das fontes alimentares mais importantes e estratégicas para o as regiões tropicais e subtropicais do mundo (FILHO et al., 2005). E por ser uma planta que apresenta tolerância à seca, pode ser cultivado em diferentes condições de clima e solo (NEVES et al., 2011).

O feijão-caupi BRS Guariba possui tegumento branco, é resistente a inúmeras doenças e possui boa adaptabilidade em diferentes ecossistemas do país, especialmente nas regiões Norte, Nordeste, e Centro Oeste, aonde a sua área de produção vem se expandindo, principalmente como alternativa para cultivo em safrinha (GONÇALVES et al., 2009).

Atualmente a cultivar BRS Guariba foi exportada para países como Índia, Turquia, Canadá, Portugal, Israel e Egito, onde teve grande aceitação alavancando assim, o mercado de feijão-caupi (GONÇALVES et al., 2009).

No Brasil, principalmente nas Regiões Norte e Nordeste, o feijão-caupi constitui uma das principais alternativas sociais e econômicas de suprimento alimentar e geração de emprego especialmente para populações rurais. Atualmente sua importância vem crescendo também em outras regiões do país (FILHO et al., 2005).

\section{RELATO DE EXPERIÊNCIA}

O experimento foi realizado no Instituto Federal de Educação, Ciência e tecnologia do Maranhão-Campus Codó, localizado a 5 km da sede do município de Codó- MA, Povoado Poraquê, Zona Rural, S/N, com as coordenadas geográficas de $4^{\circ} 26^{\prime} 51^{\prime}$ 'S, $43^{\circ} 52^{\prime}$ 57' $\mathrm{O}$ e

\footnotetext{
${ }^{1}$ Graduanda em Agronomia; IFMA-Campus Codó, antoniafirmino.ar@gmail.com

${ }^{2}$ Graduando em Agronomia; IFMA-Campus Codó, sebastiaojesus9615@gmail.com

${ }^{3}$ Graduanda em Agronomia; IFMA-Campus Codó, loirycarria@ gmail.com

${ }^{4}$ Graduanda em Tecnologia em Alimentos; IFMA- Campus Codó, eulanerys@ gmail.com

${ }^{5}$ Mestre em Agronomia, IFMA-Campus Codó, maiany.carvalho@ifma.edu.br
} 
com altitude de $48 \mathrm{~m}$. As atividades tiveram início no dia 16/03/2017 com a limpeza e demarcação da área a ser plantada, onde o dimensionamento da área ficou 11X4 sendo 44 metros quadrados para as duas parcelas considerando 1 metro de corredor para separar uma parcela da outra. A limpeza da área fora feita manual com auxílio de enxadas e ancinhos.

Uma semana após a limpeza e demarcação da área fora feito o plantio, com a abertura das covas entre 2 e $3 \mathrm{~cm}$ para as duas áreas, na segunda semana em que o plantio já havia sido realizado foi feito o replantio das covas que não obtiveram êxito na germinação. Levando em consideração uma parcela para utilizar o controle mecânico (capina) e a outra parcela sem nenhuma forma de controle. O espaçamento utilizado fora de $15 \mathrm{~cm}$ entre plantas utilizando um adensamento na cultura com intuito de reduzir a comunidade de plantas daninhas e $50 \mathrm{~cm}$ entre fileiras, utilizando 4 sementes por cova. Uma semana após o plantio já pôde-se observar a germinação das sementes, duas semanas após a germinação total das plântulas fora feito o primeiro desbaste nas plântulas retirando sempre as menos desenvolvidas.

Aos vinte dias após o plantio fora realizada a primeira capina de uma das parcelas para que fosse feita a observação da utilização e da não utilização da capina para que fosse comparada, aos 40 dias após o plantio a segunda capina foi realizada.

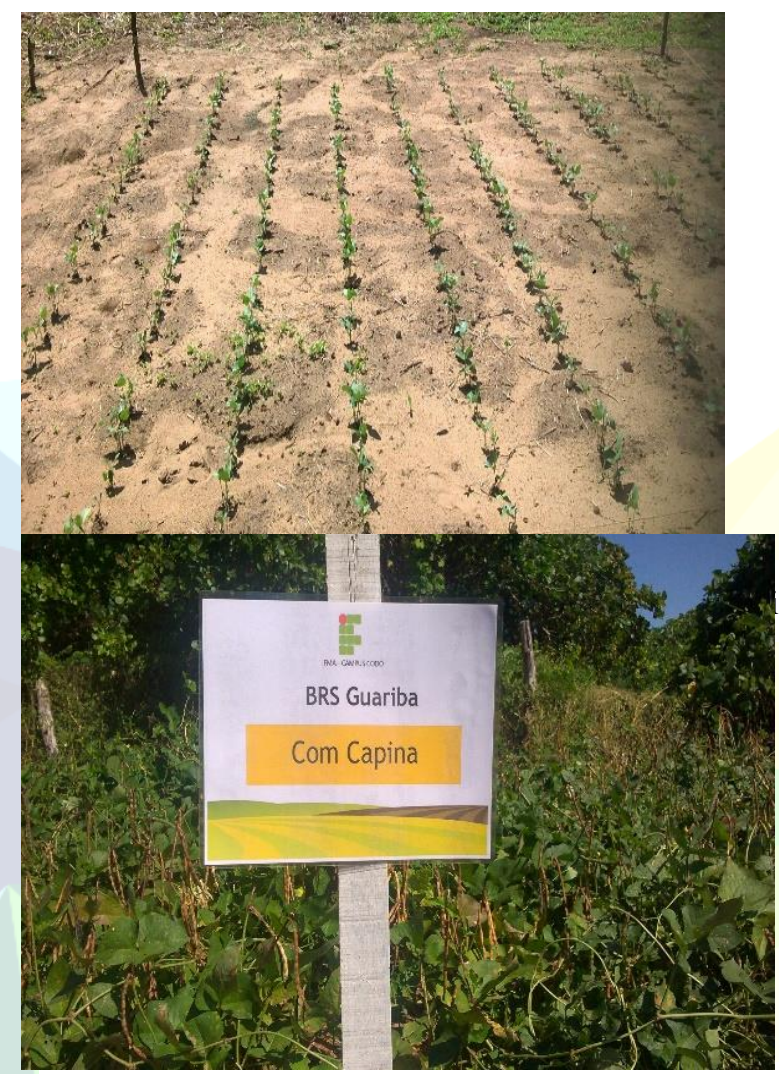

Figura 3. Plantio com capina

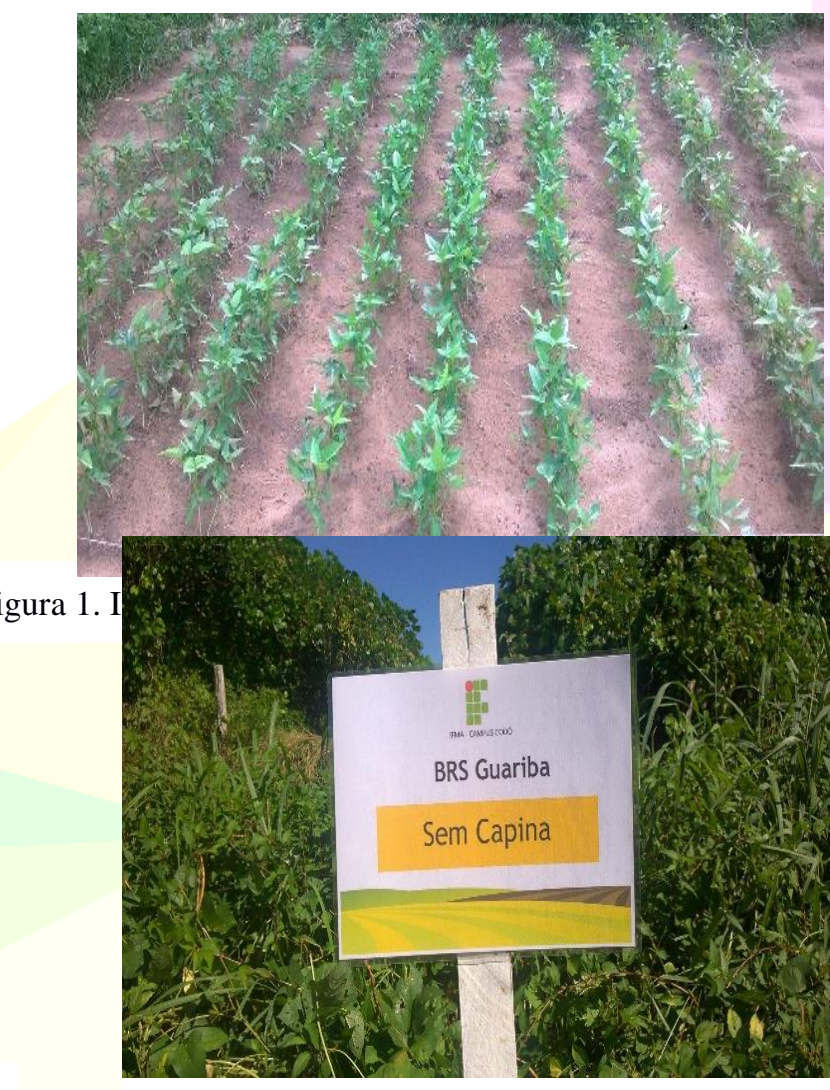

Figura 4. Plantio sem capina 


\section{CONSIDERAÇÕES}

Os resultados obtidos com as duas parcelas foram completamente diferentes, uma vez que mesmo com o adensamento da cultura houve diferença por conta da utilização do controle em uma das parcelas e a outra sem nenhuma forma de controle, onde já no estádio reprodutivo pôde-se observar a redução na produtividade.

\section{REFERÊNCIAS}

Adão Cabral das Neves, José Alves da Silva Câmara, Milton José Cardoso, Paulo Henrique Soares da Silva, Candido Athayde Sobrinho / Teresina, PI Novembro, 2011. www.infoteca.cnptia.embrapa.br/ acesso em: 15/10/2018

Feijão-caupi: avanços tecnológicos / editores técnicos, Francisco Rodrigues Freire Filho, José Albésio de Araújo Lima, Valdenir Queiroz Ribeiro. - Brasília, DF: Embrapa Informação tecnológica, 2005.

José Ricardo Pupo Gonçalves, José Roberto Antonio Fontes, Miguel Costa Dias, Maurisrael Moura Rocha, Francisco Rodrigues Freire Filho / 76I SSN 1517-3887 Dezembro, 2009 Manaus, AM. www.infoteca.cnptia.embrapa.br/ acesso em:15/10/2018. 